DEPARTAMENTO DE DOENÇAS INFECTUOSAS E PARASITARIAS

Diretor: Prof. Laerte M. Guimarães

DEPARTAMENTO DE HIGIENE E POLICIA SANITARIA ANIMAL

Diretor: Prof. T. Lion de Araujo

\title{
OCORRENCIA DA NUTALIOSE EM EQUINOS PURO SANGUE DE CORRIDAS, EM SÃO PAULO
}

(NUTTALIOSIS OCCURRENCE IN TIOROUGHIRED HORSLS, IN S. PAUIA)

Laerte M. Guimarães

T. Lion df: Aratjo Paulo M. G. de Lacerda JR. Assistente

1 estampa ( 3 figuras)

O gênero Nuttalia, França 1910 encerra babesídios frequientemente parasitas de equídeos e uma de suas espécies a $N$. equi (Laveran 1901) é o agente etiológico da nutaliose ou tristeza do cavalo. Esta espécie é pràticamente cosmopolita, tendo sido sua ocorrência assinalada na Europa (Itália, Rússia, França e Balcãs), Ásia (Transcaucásia, Turquestão, India, Annam), Africa (União Sul. Africana, Cabo, Natal, Transvaal, - Madagascar) e América do Sul.

No Brasil, a primeira observação documentada da presença da $N$. equi (Laveran 1901) é a de Carini (1910). Êste autor, examinando em São Paulo esfregaços de sangue de cavalo que lhe haviam sido enviados pelo Dr. P. Maugé, encontrou hematozoários por êle reconhecidos como "piroplasmas" e possivelmente Piroplasma equi.

Parreiras Horta \& Figueiredo (1914) publicaram resultados de suas observaçōes em Minas Gerais na cidade de Oliveira e na Vila de Passa Tempo, onde estudaram uma enzootia dos equídeos da região, conhecida pelos nomes de "mijadeira" e "curso". No sangue de poldros doentes encontraram determinado parasita e classificaram-no como Nuttalia equi (Laveran 1901), esclarecendo assim tratar-se de uma enzootia de nutaliose ou tristeza do cavalo. Os animais doentes, observados, estavam parasitados por carrapatos, identificados como Amblyoma cajennense (Fabr., 1787) e, segundo os autores, seria êsse no seu modo de ver o ixodídeo transmissor da nutaliose equina no Brasil.

Desde a publicação dos trabalhos de Carini e de Parreiras Horta \& FiguelREDO nada mais registra a literatura nacional sôbre a tristeza do cavalo. Parece-nos que durante todo êsse tempo, ou os casos de nutaliose equina no Brasil tornaram-se muito raros, como conseqüência do combate ao carrapato, particularmente nos últimos anos com o aparecimento de acaricidas eficientes, ou passaram despercebidos ou, por último, o que é mais provável, foram confundidos 
com outras doenças. $E^{\prime}$ o que se pode inferir do silêncio da literatura indigena sôbre o assunto. No entanto, desde alguns anos, vimos ohservando em equídeos puro sangue de corrida, na Vila Hipica do Jockey Club de São Paulo, e em alguns Haras, conjunto de sintomas, como febre, ictericia, hemoglobinúria, que faz pensar na tifose e na anemia infecciosa do cavalo e que, posteriormente, pudemos demonstrar tratar-se de nutaliose, como passamos a descrever.

Observações clínicas. - Desde aproximadamente 1942 vimos observando em animais de ambos os sexos e de idades variáveis de 2 a 8 anos, alojados nas cocheiras do Jockey Club de São Paulo, na bairro de Cidade Jardim, doença febril de evolução aguda, caracterizada por anemia, intensa icterícia, edema e hemoglobinúria. Em alguns casos o exame clínico revelou congestão pulmonar, pleuriz e perturbaçōes digestivas. Em raros casos observamos perturbações locomotoras. O aparecimento concomitante de vários casos dava-nos a impressão de tratar-se de doença transmissível, pois, por vêzes, êles se sucediam. atacando animais alojados nos mesmos grupos de cocheiras. Alguns dos casos observados foram fatais; a maioria, porém, apesar da terapêutica instituida ter sido puramente sintomática, evoluia para a cura. A doença manifestava-se sempre com muito maior gravidade em animais adultos, nos quais, como regra, observamos a maioria dos sintomas referidos acima, sendo quase sempre fatal, quando havia comprometimento do aparelho respiratório. Em potros, comumente, reduziam-se os sintomas a febre e icterícia que, na maioria dos casos, cediam fácilmente à terapêutica sintomática.

De início pensamos, como aliás sucedeu com outros clínicos, na possibilidade de tratar-se de tifose ou de anemia infecciosa, mas, a não contagiosidade. direta, a baixa letalidade, a falta de resposta à medicação indicada para tais casos, enquadrando-se a sintomatologia geral na que ocorre em outras babesioses, a curva térmica do tipo remitente e, finalmente, a possibilidade de observar maior número de casos, levaram-nos à suspeita de nutaliose, posteriormente confirmada por provas de laboratório.

Em janeiro dêste ano, um de nós (L. M. G.), teve oportunidade de 'examinar dois potros puro sangue, de dois anos de idade, procedentes de um Haras de São Caetano do Sul e que se encontravam, há seis meses, na Vila Hípica do Jockey Club de São Paulo. À anamnese verificamos que os animais apresentavam inapetência há dois dias. Ao exame clínico verificamos síndroma febril icteríco. Julgando tratar-se de infecção prescrevemos penicilina e sulfas. No dia seguinte, a temperatura voltou ao normal, pela manhã, e mostrou tendência a elevação à tarde, persistindo essa oscilação por três dias. Após êsse período hou ve acentuada elevação térmica (39.6 no quarto dia, 40.4 no quinto dia), com intensificação da icterícia, aparecimento de edema das partes en declive e hemoglobinúria. 
Diante da agravação dos sintomas e admitindo-se a presença de germe não sensível à medicação instituida, passamos ao emprêgo da estreptomicina. A temperatura voltou ao normal no sétimo dia da doença, ou seja, após 19 horas do início das aplicações de estreptomicina e manteve-se entre 38.1 e 39 até ao nono dia, quando houve recrudescimento, chegando a 40.5 no décimo dia.

Nessa ocasião, considerando o malôgro da medicação e a evolução da doen. ça, passamos a pensar na possibilidade de tratar-se de uma babesiose. apesar de não surpreendermos carrapatos nos animais e do tratador afiançar nunca os haver encontrado nos animais a seu cuidado. O exame de esfregaços de sangue confirmou inteiramente a hipólese, pois, encontramos hemátias parasitadas por hematozoários do tipo dos babesídeos. O emprêgo de medicação específica deu como resultado o desaparecimento rápido dos sintomas, com volta da temperalura ao normal após 18 horas.

\section{INOCULAÇOES EXPERIMENTAIS}

De um dos animais acima citados, logo após a obtenção de esfregaços positivos e antes da aplicação do específico, foram retirados $20 \mathrm{~cm}^{3}$ de sangue $\mathrm{e}$ recolhidos a frasco con citrato de sódio, os quais foram inoculados por via sub. cutânea num cavalo mestiço, com aproximadamente 10 anos de idade. Este animal foi submetido a observação diária — tomadas de temperatura e exames do sangue - durante dois meses, sem apresentar qualquer sintoma de nutaliose ou qualquer forma de parasita no sangue.

Dado o conhecimento de que um ataque por babesídeos confere aos animais resistência à reinfestação e como o cavalo inoculado podia estar premunido ou ter uma resistência natural maior que a dos de raças apuradas, procuramos repetir a inoculação usando animal puro sangue inglês. No mesmo animal que havia fornecido sangue para a primeira inoculação, fizemos, dois meses após, nova sangria. (O fornecedor do sangue nesta ocasião já estava clinicamente são, mas, a exemplo do que sucede na babesiose bovina, deveria albergar os parasitas em seu organismo.

A 27-3-50 inoculamos $70 \mathrm{~cm}^{3}$ de sangue citratado, por via subcutânea, em uma potranca puro sangue inglês, de dois anos de idade. A potranca inoculada foi considerada em estado normal, graças aos exames realizados. Nos dez primeiros dias após a inoculação, nada de anormal foi observado. No décimo primeiro dia, pela manhã, a temperatura elevou-se a 39.4. No mesmo dia à tarde a temperatura baixou para 38.5 e nos esfregaços de sangue corados pelo Giemsa, foram observadas numerosas formas do parasita. Nos dias subsequentes novas formas foram observadas nas hemátias, inclusive as típicas em cruz de Malta. Esse animal conlinuou a apresentar parasitas demonstráveis em esfregaços de sangue até o dia 9 de maio. Depois desta data os exames de sangue foram sempre 
negativos. Os sintomas observados neste caso de doença experimental foram semelhantes àqueles vistos nos casos espontâneos.

$O$ parasita. - Em todos os casos em que nos foi possível examinar o sangue dos animais infetados, encontramos babesídeo por nús identificado como a Nuttallia equi (Laveran 1901). Este hematozoário apresenta-se de acôrdo com a fase da doença, sob forma de parasita pequeno, redondo ou oval, ou sol, forma de corpúsculo lembrando um anaplasma. Muito típicas são as formas em cruz de Malta, constituidas por quatro elementos piriformes, dispostos em cruz. As medidas por nós tomadas coincidem com as indicadas por diversos especialistas no assunto; assim, os parasitas piriformes apresentam diâmetro máximo de $2.32 \mu$. No início da doença, no sangue periférico, predominam as formas anaplasmoides, enquanto as piriformes e em cruz de Malta são abundantes em fases posteriores.

Outros casos. - Além dos dois primeiros casos diagnosticados e tratados como foi descrito acima, tivemos oportunidade de verificar e tratar, no Jockey Club, até ao presente, mais seis casos, diagnosticados pelo exame clínico, que foi, em todos êles, confirmado pelo encontro do parasita em esfregaços de sangue. Todos êstes animais responderam prontamente à medicação especifica. Três outros potros, também acometidos de nutaliose diagnosticada clinicamente, foram tratados, sem têrmos tido oportunidade de realizar os exames de sangue e se restabeleceram sem maiores contratempos.

Tratamento. - Uma vez estabelecido o diagnóstico de nutaliose. usamos como específico soluçōes a $5 \%$ de metil-sulfometilato de uréia da 6 -aminoquiroleína, por via subcutânea e em doses variáveis de 1 a $4 . \mathrm{cm}^{3}$. Obtivemos em todos os animais amplo sucesso, conseguindo curas clínicas, algumas vềzes em 24 horas e com uma única aplicação de $4 \mathrm{~cm}^{3}$ do medicamento, na concentração acima referida. Alguns animais, após a injeção do medicamento, mostraram diversos tipos de reaçĩo sempre pouco intensa, como tremores, suores, inquietação e cólicas intestinais que regrediam espontâneamente.

Transmissão. - A nutaliose é veiculada por ixodídeos, e, entre êsles, jỉ fo. ram assinaladas, como transmissoras, as seguintes espécies: Rhipicephalus evertsi, Neumann, 1817 - na Africa Meridional; R. bursa, Canestrini e Fanzago, 1878 - na Itália; Dermacentor sp., na Rússia. No Brasil, Parribas IIorta \& FiguerREDo lembram a possibilidade do Ablyomma cajannense (Fabr., 1787) ser o transmissor.

No Jockey Club de São Paulo, como dissemos acima, os animais aí mantidos não são habitualmente infestados por carrapatos; entretanto, a hipótese de serem parasitados, em rápidos períodos, não pode ser desprezada. A alimentação verde dêsses animais é obtida diäriamente en campos e terrenos baldios da 
várzea do Butantã e proximidades, onde se tem verificado de sobêjo a ocorrência de carrapatos. O capim cortado nesses locais pode carrear ninfas que se fixam aos animais e são dentro de pouco tempo retiradas pela ação da raspadeira. Aliás, numa única oportunidade, um de nós (T. L. A.) pôde encontrar num potro, um só exemplar fêmea de Boophilus microplus fixado ao abdome, próximo à regiāo inguinal. Este fato indica que pode ocorrer o mesmo, e com maiores possibilidades, quanto às espécies do gênero Amblyomma, dadas suas particularidades biológicas.

\section{RESUMO}

Os AA. descrevern casos de nutaliose equina, em cavalos puro sangue inglês, observados em São Paulo. Reproduzem experimentalmente a doença, descrevem as formas do agente eliológico - Nuttalia equi (Laveran 1901) - encontradas em esfregaços de sangue e assinalam o sucesso do tratamento com solução a $5 \%$ de metil sulfometilado de uréia da 6-aminoquinoleína.

\section{ABSTRACT}

The AA. describe the occurrence of equine nuttaliosis in race horses, in São Paulo. They reproduced the disease experimentaly, described the forms of the etiological agent - Nuttalia equi (Laveran 1901) - which they found in blood smears and consider the therapeutics success with the use of $5 \%$ urea-dimethylquinolyl sulfate solutions.

\section{BIBLIOGRAFIA}

Wenion, C. M. - 1926 - Protozoology. London, Baillière, Tindall and Cox

Canplanter, G. - 1939 - Parasites et maladies parasitaires des équides domestiques. Paris, Vigot frères

Iutria, F. - Mank, J. \& Manninger, R. - 1938 - Special pathology and therapeutics of the diseases of domestic animals. 4th English ed. London, Baillière, Tindall and Cox

Neveu-Jamanis, M. 1943 -.. Traité de Protozoologie médicale et vétérinaire. Paris, Vigot frires

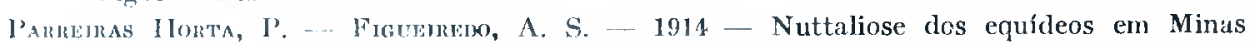
Gerais. "A mijadeira" dos poldrinhos". Rev. Vet. e Zoot., R. Janeiro, 4(1):3

('arin, $A$. 1910 - Sobre uma piroplasmose equina observada em São Paulo. $A r c h$. soc. Med. Cir., S. Paulo, 1(2):

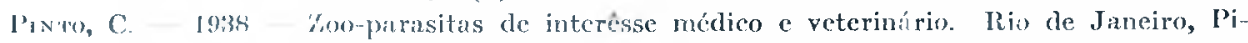
menta de Mcllo \& Cia.

Curasson, Gr. - 1946 - Malidies infectieuses des animaux domestiques. Paris, Vigot frères 

I. M. Guimarães, T. I. Araujo e I'. Iacercla .JP. - Nutaliose em equinos

Estampa 1

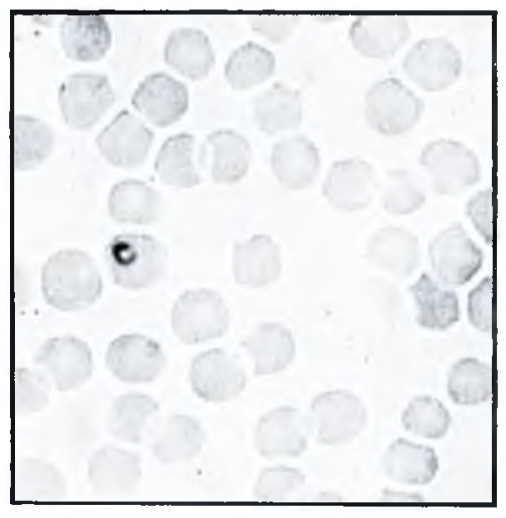

Fig. 1 Hemento ghoboso.

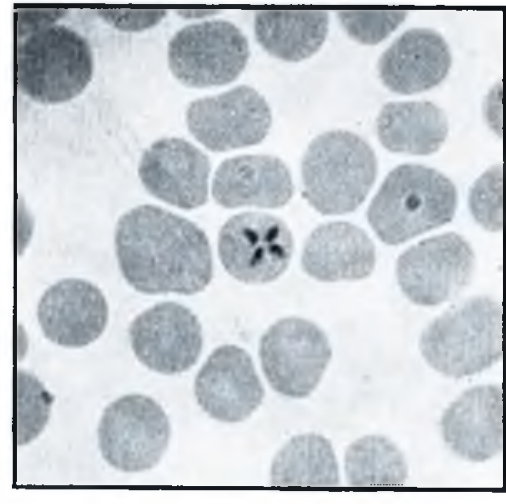

lig. " - Forma em Crü de Malta.

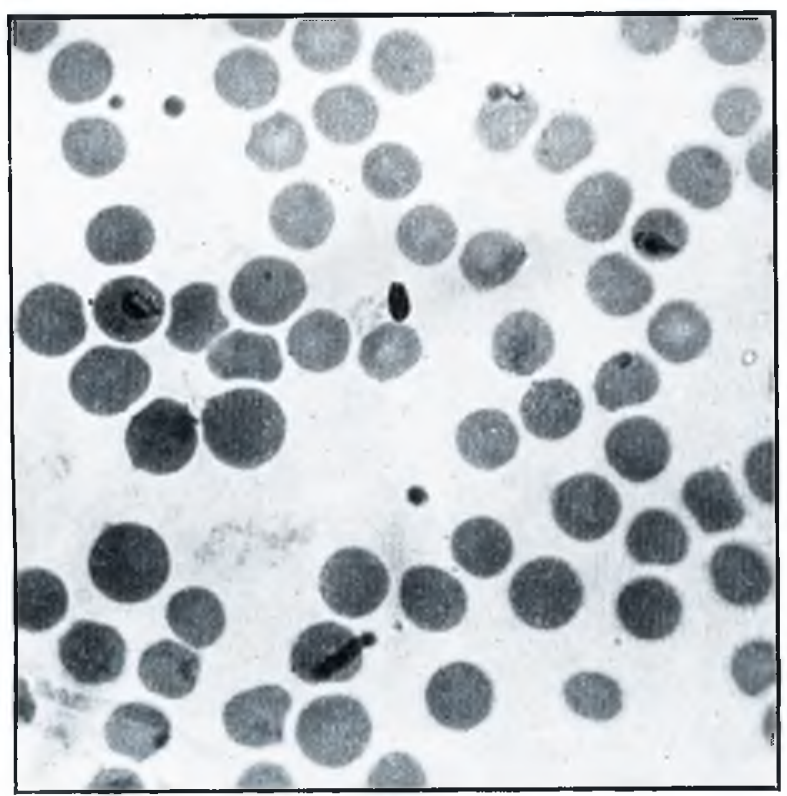

Fig. 3 - likementos piriformes. 